УДК 78.01+78.082.2

DOI https://doi.org/10.31723/2524-0447-2019-29-2-5

Татьяна Александровна Шевченко

ORCID: 0000-0002-5915-2426

кандидат искусствоведения,

концертмейстер кафедры сольного пения

Одесской национальной музыкальной академии имени А. В. Неждановой,

член общественной организации

«Сообщество «Музыковеды Украины в мировой культуре»

tatashev89@gmail.com

\title{
СОНАТА-ВОСПОМИНАНИЕ КАК ВЕРШИНА АВТОРСКОЙ СИМВОЛИКИ Н. МЕТНЕРА
}

Цель работы заключается в исследовании фортепианного творчества Н. Метнера, выявлении композиционных и стилевых принципов композиторской и исполнительской интерпретации фортепианных сонат Н. Метнера как особого жанрово-стилевого феномена в контексте хронотопического подхода на примере Сонаты-воспоминание, соч. 38 № 1. Методология исследования обусловлена использованием аналитического, биографического, историко-логического, компаративного методов. Методологическую основу исследования образует системный историко-теоретический музыковедческий анализ стилевого содержсания музыкального творчества. Научная новизна работы основана на сравнении графического анализа нотного текста Сонаты-воспоминание и его звукового воспроизведения, представленного в виде «Исполнительской партитуры ремарок». Впервые анализируются некоторые особенности исполнения Сонаты-воспоминания рядом концертирующих пианистов. Выводы. Впервые предложенная «Исполнительская партитура ремарок» дает дополнительное к нотному тексту графическое видение процесса преобразований образов произведения со стороны фразировки, артикуляции, динамики, темповых градаций, педальных эффектов, что дает возможность сделать музыкальное повествование интонационно более ясным, отделив лирическую сферу от моторной, драматическую от элегической. В своей работе мы апеллируем к предлагаемым, на наш взгляд, достаточно объективным методам исследования исполнительского музыкознания - анализу ряда исполнительских ремарок, данных автором в нотном тексте сонаты, а также к "Исполнительской партитуре ремарок», позволяющие выявить степень точности следованию авторскому замыслу со стороны исполнителей, а также объем индивидуального прочтения произведения крупнейшими пианистами мира. На базе «Исполнительской партитуры 
ремарок» автором статьи исследованы доминирующие свойства сонат для фортепиано Метнера, повлиявшие на исполнительский стиль пианистов ХХІ века.

Ключевые слова: Н. Метнер, соната, ремарка, интерпретация, программность, «Исполнительская партитура ремарок».

Shevchenko Tatyana Aleksandrovna, Ph.D. in Art History, Concertmaster at the Solo Singing Department of Odessa National A. V. Nezhdanova Academy of Music, Member of the Public Organization "Community "Musicologists of Ukraine in world culture"

Sonata-reminiscenza as the top of the author's symbolism of N. Medtner

Objective of the work is to study the piano work of $N$. Medtner, to identify the compositional and stylistic principles of the composer's and performing interpretation of $N$. Medtner's piano sonatas as a special genre-style phenomenon in the context of the chronotopic approach, on the example of the Sonata-reminiscenza, op. 38 No.1. The methodology is based on the use of the analytical, biographical, historical-logical, comparative methods. The methodological basis of the research is formed by a systemic historical and theoretical musicological analysis of the stylistic content of musical creativity. The scientific novelty of the work is based on a comparison of the graphical analysis of the musical text of the Sonata-reminiscenza and its sound reproduction, presented in the form of the "Performance score of remarks". For the first time, are analyzed some performance features of the Sonata-reminiscenza by a number of concert pianists. Conclusions. The "Performance score of remarks" provides an additional graphic vision of the process of transforming the images of this work on part of the phrasing, articulation, dynamics, tempo gradations and pedal effects. It must help to make the musical narration more clear, separating the lyrical sphere from the motoric, the dramatic sphere from the elegiac. In our work, we appeal to the objective methods of researching performing musicology, - the analysis of a number of performing directions given by the author in the musical text of the sonata, as well as to the "Performing score of remarks", which allow us to reveal the degree of accuracy in following the author's intention on the part performers, as well as the volume of individual reading of the work by the world's largest pianists.

Key words: N. Medtner, sonata, remark, interpretation, programming, "Performance score of remarks".

Шевченко Тетяна Олександрівна, кандидат мистецтвознавства, концертмейстер кафедри сольного співу Одеської національної музичної академії імені А. В. Нежданової, член громадської організації "Спільнота «Музикознавці України у світовій культурі»

\section{Соната-спогад як вериина авторської символіки М. Метнера}

Мета роботи полягає в дослідженні фортепіанної творчості M. Метнера, виявленні композиційних $i$ стильових принципів композиторської та виконавської інтерпретації фортепіанних сонат М. Метнера як особливого жанрово-стильового феномена в контексті 
хронотопічного підходу на прикладі Сонати-спогад, соч. 38 № 1. Методологія дослідження зумовлена використанням аналітичного, біографічного, історико-логічного, компаративного методів. Методологічну основу дослідження утворює системний історико-теоретичний музикознавчий аналіз стильового змісту музичної творчості. Наукова новизна роботи полягає в порівнянні графічного аналізу нотного тексту Сонати-спогад і його звукового відтворення, представленого у вигляді «Виконавської партитури ремарок». Уперше аналізуються деякі особливості виконання Сонати-спогад у виконанні піаністів-концертантів. Висновки. Уперше запропонована «Виконавська партитура ремарок» дає додаткове до нотного тексту графічне бачення процесу перетворень образів твору з боку фразування, артикуляції, динаміки, темпових градацій, поділених ефектів, що дає можливість зробити музичне оповідання інтонаційно яснішим, відокремивши ліричну сферу від моторної, драматичну від елегійної. У своїй роботі ми апелюємо до пропонованих, на наш погляд, досить об'єктивних методів дослідження виконавського музикознавства - аналізу ряду виконавських ремарок, даних автором у нотному тексті сонати, а також до «Виконавської партитури ремарок», що дозволяє виявити ступінь точності слідування авторському задуму з боку виконавців, а також дає можливість оцінити обсяг індивідуального прочитання твору талановитими піаністами світу. На базі «Виконавської партитури ремарок» автором статті виявлено домінівні властивості сонат для фортепіано Метнеpa, що вплинули на виконавський стиль піаністів ХХІ століття.

Ключові слова: М. Метнер, соната, ремарка, інтерпретація, програмність, «Виконавська партитура ремарок».

Актуальность темы исследования. Творчество Н. Метнера композитора и исполнителя - в значительной мере связано с фортепиано, которому «он доверял свое вдохновение, и помог открыть новые возможности фортепьянных звучаний, столь непохожие на звучания других авторов» [1]. В связи с этим А. Гольденвейзер приходит к выводу, что «он близок к Шопену, который был еще более замкнут» [2].

Большинство фортепианных сонат Н. Метнера относится к числу его лучших сочинений. В 1916 году композитор получил вторую Глинкинскую премию (по фонду М. Беляева) именно за произведения такого жанра (соната g-moll op. 22 и «Соната-баллада» Fis-dur op. 27), что является несомненным подтверждением успешного решения композитором самых сложных задач сонатной формы. По мнению А. Гольденвейзера, «едва ли кто-нибудь из композиторов после Бетховена владел в таком совершенстве сонатной формой, как Метнер» [2]. 
Цель работы: исследовать сонатное творчество Н. Метнера, выявить его специфические особенности на примере Сонаты-воспоминание, соч. 38 № 1 в исполнении ведущих концертирующих пианистов.

Научная новизна работы основана на сравнении графического анализа нотного текста Сонаты-воспоминание и его звукового воспроизведения, представленного в виде «Исполнительской партитуры ремарок». Впервые анализируются некоторые особенности исполнения Сонаты-воспоминания рядом концертирующих пианистов.

Основное содержание. С фортепиано в композиторском творчестве Н. Метнера связаны различные жанры - три концерта с оркестром, свыше тридцати сказок, три цикла и ряд других пьес (импровизации, дифирамбы, элегии). Но особое место в фортепианном наследии Н. Метнера занимают сонаты, вызывающие ассоциации «с горным хребтом, на протяжении которого высятся четырнадцать самостоятельных вершин, ни в чем друг с другом не схожих» [1]. Причем композитор обращался к жанру фортепианной сонаты на протяжении всей своей творческой жизни (со второй половины 1890-х до 30-х гг. ХХ ст.), так что «можно сказать, что основная идея, первичный смысл сонатной формы им, как немногими композиторами послебетховенского времени, разгадан» [1].

Большую роль в популяризации творчества Н. Метнера сыграли его собственные авторские интерпретации, становившиеся крупнейшими событиями художественной жизни русских городов до его отъезда за границу. Вспомним рассуждение Г. Нейгауза о том, что «на протяжении веков среди имен величайших пианистов мы всегда назовем в первую очередь Баха, Моцарта, Скарлатти, Бетховена, Шопена, Листа, Рахманинова, Скрябина, Метнера» [3]. Н. Метнер никому не доверял премьеры своих произведений, что сыграло как положительную, так и, возможно, отрицательную роль в широком распространении его композиторского творчества.

По мнению Н. Мясковского, в каждой из тем у Н. Метнера оказывается «такой оборот, которым эти темы как бы цепляются за душу, за память, <..> большинство метнеровских тем обладает точно каким-то крючком» [4]. Критик указывал, что лишь самые выдающиеся художники - Р. Вагнер, Л. Бетховен, А. Скрябин - имеют подобные темы. Задача поиска такого «интонационного крючка» и его последующего сознательного 
развертывания (через варьирование и мотивное развитие, принципы монотематизма) в процессе исполнения сонаты и стоит перед пианистом, исполняющим фортепианную музыку Н. Метнера. Проводником в этом вопросе, безусловно, является сам композитор, оставивший значительное число ремарок в своих сонатах.

«Соната-воспоминание» (ор. 38), которую Метнер любил более других своих фортепианных сонат, вошла в цикл «Забытых мотивов». Музыка анализируемой сонаты лишена внешней броскости или виртуозности и закономерно, что Г. Нейгауз направляет исполнителей на поиск в музыкальном тексте этой сонаты лирико-созерцательного эмоционального состояния с драматическими элементами. По его словам, ««оната-reminiscenza» и впрямь является не только рассказом, но и воспоминанием о чем-то давно минувшем $<\ldots>$ Цикл «Забытые мотивы» <...> настойчиво возвращает к прошлому < ..> его музыка наполнена чувством благоговения и любви к действительно прекрасному, славному прошлому» [1].

Написана «Соната-воспоминание» в период ожидаемого Метнером отъезда из России (в Буграх). Вероятно, что грусть и нежная поэзия этой музыки соответствовали тому настроению, в котором композитор находился вдали от городской суеты, как бы наедине с собой. Благодаря воспоминаниям А. Трояновской узнаем о первом исполнении автором произведения в домашней уютной обстановке: «Полное наше одиночество в лесу, зима за темными окнами его комнаты и богатство фортепианной звучности под его руками - все это производило на нас совершенно волшебное впечатление» [5].

Концентрированность мыслей и чувств в музыке Сонаты повлекла за собой стремление автора как можно более тщательно отразить в нотном тексте свои пожелания и рекомендации для исполнителей.

Последовательно выстроив все авторские исполнительские ремарки, мы получим таблицу, из которой становится очевидным, что круг ремарок и достаточно разнообразен, и весьма своеобразен. Образность ремарок, их максимально возможная точность соответствия авторскому замыслу, представлялась Н. Метнеру особым «маяком», направляющим исполнителя в его поисках. Композитор не страшился их непривычности - важнее было найти наиболее меткую, а то и единственную (с его точки зрения) из словесных характе- 
ристик. Из полученного списка можно выделить несколько групп терминов, которые дадут исполнителю картину настроения Сонаты-воспоминания.

\section{Н. МЕТНЕР. «СОНАТА-ВОСПОМИНАНИЕ»} ИСПОЛНИТЕЛЬСКИЕ РЕМАРКИ

\begin{tabular}{|c|c|c|}
\hline Итальянский термин & перевод & $\begin{array}{c}\text { частота } \\
\text { употребления }\end{array}$ \\
\hline Agitato & Взволнованно & 1 \\
\hline All'improvisa & Неожиданно & 1 \\
\hline Allargando & Расширяя & 4 \\
\hline Apassionato & Страстно & 1 \\
\hline Calmando & Успокаиваясь & 2 \\
\hline Cantabile & Певуче & 2 \\
\hline Cantando & Певуче, распевая & 6 \\
\hline Concentrando & Сосредоточенно & 4 \\
\hline Danzando & Танцевально & 1 \\
\hline Dolce, simplice & Нежно, просто & 1 \\
\hline Espressivo & Выразительно & 15 \\
\hline Giocoso & Радостно, весело & 1 \\
\hline Leggierissimo & Легчайше & 1 \\
\hline Leggiero & Легко & 3 \\
\hline Meditamente & созерцательно, & 1 \\
\hline Росо lusingando & Чуть вкрадчиво & 2 \\
\hline Poco maestoso & $\begin{array}{c}\text { Чуть величаво, } \\
\text { торжественно }\end{array}$ & 1 \\
\hline Risoluto & Решительно & 3 \\
\hline Semplice & Просто & 1 \\
\hline $\begin{array}{c}\text { Sempre espressivo } \\
\text { e disinvolto }\end{array}$ & $\begin{array}{c}\text { Все время выразительно } \\
\text { и непринужденно }\end{array}$ & 1 \\
\hline Sostenuto & Сдержанно & 2 \\
\hline Svegliando & Пробуждаясь & 1 \\
\hline Tenebroso & Мрачно & 1 \\
\hline Tranquillo & Спокойно & 3 \\
\hline & & \\
\hline & & 15 \\
\hline
\end{tabular}

Наиболее активно применяется Н. Метнером термин espressivo, который употребляется как самостоятельно, так и 
в сочетании с другими ремарками, что указывает на многообразие образно-поэтических оттенков выразительной игры:

- «непринужденно» (Sempre espressivo ed isinvolto- начало сонаты, первые 16 тактов),

- «созерцательно размышляя» (Espressivo meditamente TT. $61-83)$,

- «очень певуче» (Molto cantabile ed espressivo тт. $114-118)$,

- «подчеркивая» (Espressivo marcato - тт. 133 - 137), что указывает на артикуляционную манеру произнесения в партии левой руки и требует от исполнителя интенсивной атаки звука;

- «спокойно» (Tranquillo ed espressivo - тт. 198 - 214); особо отметим, что использование такой ремарки предостерегает исполнителя от увлечения экспрессией и излишней насыщенности звука;

- «чуть весело» (Росо giocoso, ma sempre espressivo тт. 301 - 308); ремарка указывает на характер игры, сохраняющий свою выразительность даже в расчлененном исполнении при staccato под лигой. Несмотря на обособленность каждого звука, они объединены выразительностью фразировки;

- «связно» (Sempre espressivo legato - тт. 340 - 357); указанные фразы расположены в верхнем голосе партии правой руки, и эта ремарка предполагает связное и насыщенное звучание, подобное технологии извлечения звуков на струнном инструменте (скрипке) - на одном смычке.

Достаточно активно в нотном тексте сонаты применяются ремарки Cantabile (певуче) и характерный для образного строя H. Метнера сопутствующий ему термин Semplice (просто), а также Cantando (певуче, распевая), рядом с которым активно применяется указание Risoluto (решительно), что относится не столько к смене общего образного содержания, сколько к изменению внутри уже данной основы, связанной с манерой артикуляции.

Таким образом, анализ исполнительских ремарок указывает на особое значение в сонате кантилены, которая требует от исполнителя более глубокого туше и внимательного отношения к воплощению различных граней распевности. К числу необычных метнеровских терминов принадлежит «Пьесное туше», с которым композитор «связывал путь к достижению фортепианного «пения» (разрядка - И. Зетель). $<\ldots>$ оно четко ассоциировалось с игрой плоскими пальцами и их наивозможной близостью к клавиатуре. В сочетании с пластичностью («побольше пьесного туше и пластики» 
(разрядка - И. Зетель)) здесь открывались богатейшие возможности звуковых нюансов и градаций» [6].

Также обратим внимание на характерное для романтиков переключение образного мира сонаты с легких, жизнерадостных настроений, танцевальности (Danzando) на вкрадчивые, сумрачные (Tenebroso).

Не может быть не замечено и совместное воздействие двух ремарок (Svegliando - «пробуждаясь» и All'improvisa - «неожиданно»), которые означают «неожиданное пробуждение» и должны изменить внутренний настрой исполнителя мгновенно.

Ремарка Concentrando («сосредоточенно»), появляющаяся 4 раза в нотном тексте сонаты, подчеркивает внутреннюю сосредоточенность главного героя, погруженного в размышления-воспоминания.

Итак, анализ авторских ремарок «Сонаты-воспоминания» позволяет выделить в ней такую драматургию смен семантических модусов как:

- Сосредоточенность;

- Экспрессивное пение;

- Страстность;

- Медитативность.

Тщательное уточнение композитором своих художественных намерений требует от исполнителя внимательного прочтения этих вербальных авторских указаний.

Напомним еще раз, что для фортепианного творчества Н. Метнера, в первую очередь для центрального жанра композитора - сонат для фортепиано - характерна особая программность, суть которой заключается во взаимодействии внешних, литературно-поэтических, и внутренних, жанрово-стилистических, предпосылок музыкальной цикличности, что порождает метнеровские оригинальные и неожиданные сочетания жанрово-композиционных форм в пределах одного опуса.

Программность метнеровских фортепианных сонат имеет ярко выраженную словесно-литературную природу, поскольку композитор, в первую очередь, работает со словом и выражает свой духовный мир через Слово, давая в качестве «компаса» программное название ряду сонат, раскрывая в дневниках и письмах вербально-содержательные основы некоторых сочинений, наконец - детализируя композиционные и образные топосы своих фортепианных сонат в подробнейших словесных музыкально-исполнительских терминах - ремарках, систематизированных нами в «Исполнительской партитуре ремарок» 
(партитура включает фразировочные, артикуляционные, динамические, темповые, метро-ритмические и образные ремарки, присутствующие в нотном тексте сонат Н. Метнера). Основываясь на результатах анализа круга ремарок, присутствующих в одной из самых востребованных в исполнительской традиции сонате - «Сонаты-воспоминания»- можно выделить в ней характерный круг метнеровских образов.

«Исполнительская партитура ремарок», как инструмент анализа, предполагает, что все ремарки (словесные и графические) размещены в виде четырехлинейной «партитуры», в которой каждая линия посвящена определенным выразительным средствам. В исследовании «Исполнительские ремарки, образ мира и музыкальный стиль» А. Сокол говорит о необходимости исследования ремарок «в аспекте музыкального стиля и в рамках содержания художественного образа мира композитора. В таком аспекте ремарки, несомненно, являются репрезентантами экспрессивно-речевого стиля музыки композитора с одной стороны, и установками для ее исполнительской интерпретации - с другой, так как содержат в себе существенные признаки интонационно-художественных образов» [7].

В нашей работе впервые предложен исполнительский взгляд на содержание фортепианной сонаты Н. Метнера, основанный на сравнении графического анализа нотного текста и его звукового воспроизведения. Кроме того, нами анализируются некоторые особенности исполнения «Сонаты-воспоминания» рядом концертирующих пианистов.

«Исполнительская партитура ремарок» дает дополнительное к нотному тексту графическое видение процесса преобразований образов произведения со стороны фразировки, артикуляции, динамики, темповых градаций, педальных эффектов. Это должно помочь сделать музыкальное повествование интонационно более ясным, отделив лирическую сферу от моторной, драматическую от элегической и так далее.

Над партитурой указывается имя автора, название произведения и количество рассматриваемых тактов. Над верхней линейкой располагается тактовый размер, темп, характер движения и его изменения. Под верхней линейкой - обозначение характера интонирования (признаки музыкальных образов или их исполнения). Над второй линейкой выписываются артикуляционные лиги, а также артикуляционные словесные или графические обозначения (Legato - nonlegato, staccato) в партии правой руки пианиста. Под второй линейкой - фраза, исполняемая правой рукой пианиста. Над третьей линейкой записываются артикуля- 
ционные лиги и артикуляционные словесные или графические обозначения (Legato - nonlegato, staccato) в партии левой руки пианиста. Под третьей линейкой - фраза, образуемая в партии левой руки пианиста. Над четвертой линейкой размещены динамические указания стабильного ряда (f, p) и различных изменений (cresc., dim.), а также динамические артикуляции (sf, sff, rf). Под нижней линейкой выписываем дополнительные способы исполнения (Ped., glissando и др.).

4-ХСТРОЧНАЯ ИСПОЛНИТЕЛЬСКАЯ ПАРТИТУРА

Пример 2 верхняя строка:

\begin{tabular}{c}
\hline размер, темп, характер движения и его изменения \\
\hline $\begin{array}{c}\text { обозначение характера интонирования } \\
\text { (т. е. признаки музыкальных образов) }\end{array}$ \\
\hline
\end{tabular}

2-я строка:

артикуляционные лиги и артикуляции

(словесные или графические) в партии правой руки

фразировочные лиги в партии правой руки

3-я строка:

\begin{tabular}{c} 
артикуляционные лиги и артикуляции \\
(словесные или графические) в партии левой руки \\
\hline фразировочные лиги в партии левой руки \\
\hline 4-я строка: \\
уровни стабильной динамики \\
и процессуальные динамические оттенки \\
\hline дополнительные способы и приемы исполнения \\
(педаль, глиссандо и др.)
\end{tabular}

Сопоставив снабженный подробными ремарками нотный текст с исполнительскими интерпретациями известных пианистов Э. Гилельса и С. Рихтера, можно представить сравнительную таблицу. Как следует из фрагмента сравнительного сопоставления авторской и исполнительской интерпретации, очевидно сходство концепции обоих пианистов.

Как уже отмечалось ранее в нашей работе, словесные ремарки, адресованные Н. Метнером исполнителю в тексте сонат, на самом деле являются неотъемлемой частью общей 
музыкальной концепции, а самое главное - указывают на ее опорные топосные моменты, прокладывают путь в метнеровскую топосферу. Они определяют путь интерпретации музыкального текста и последовательно ведут к стилевой идее произведения, следовательно, и к стилевым исполнительским топосам метнеровской музыки. Подчеркнем, что стилевые намерения - интенции, планы, целесообразность - музыкального произведения могут быть выявлены только в звучащей форме, то есть реализуются исполнительскими средствами, поэтому исполнительская и композиторская поэтика фортепианных сонат Н. Метнера являет собой неделимое целое.

Запись сонаты в исполнении Эмиля Григорьевича Гилельса, «открывшего» Н. Метнера любителям музыки, относится к 1968 году. Согласно нашей исполнительской партитуре, мы выявляем романтически-эмоциональный акцент такого исполнения, что очевидно из большого числа нарастаний и спадов звучности, в том числе и в рамках одного-двух тактов, а также в достаточно значительной степени микро-ускорений и микро-замедлений в исполнении Э. Гилельса. Известный советский музыкант сожалел, что пианисты очень слабо знакомы с творчеством этого композитора и редко исполняют его произведения.

Святослав Теофилович Рихтер впервые сыграл «Сонату-воспоминание» в январе и мае 1947 г. соответственно - в Большом зале Московской консерватории и в Ленинградской филармонии, а также в декабре 1981 года в Государственном музее изобразительных искусств им. Пушкина. О самой сонате С. Рихтер замечает (в телефильме о концерте «Декабрьские вечера», на котором была исполнена «Соната-воспоминание»), что «настроение в ней как в картинах Борисова-Мусатова». Отметим своеобразную манеру исполнения этой сонаты С. Рихтером: с одной стороны, угловато-пластичная, сдержанная и, с другой стороны, свободная; в звукозаписи ощутима застенчивая и одновременно открытая подача метнеровских образов.

На основе анализа авторских указаний, а также исполнительских интерпретаций широкого круга ремарок (фразировочных, динамических, темповых, метро-ритмических, агогических и артикуляционных образных), являющихся «репрезентаторами экспрессивно-речевого стиля музыки композитора» (определение А. Сокола - см. 7), «авторская и исполнительская партитура ремарок» помогает не только дополнить характеристику стиля композитора, но и выявить особенности исполнительского подхода к фортепианным 
сонатам Н. Метнера (как самого композитора и исполнения им собственных сочинений, так и ряда наиболее ярких пианистов XX века - С. Рихтера, Э. Гилельса, М. Юдиной, Дж. Тозера, Е. Кисина, Е. Светланова и других).

Пример 3

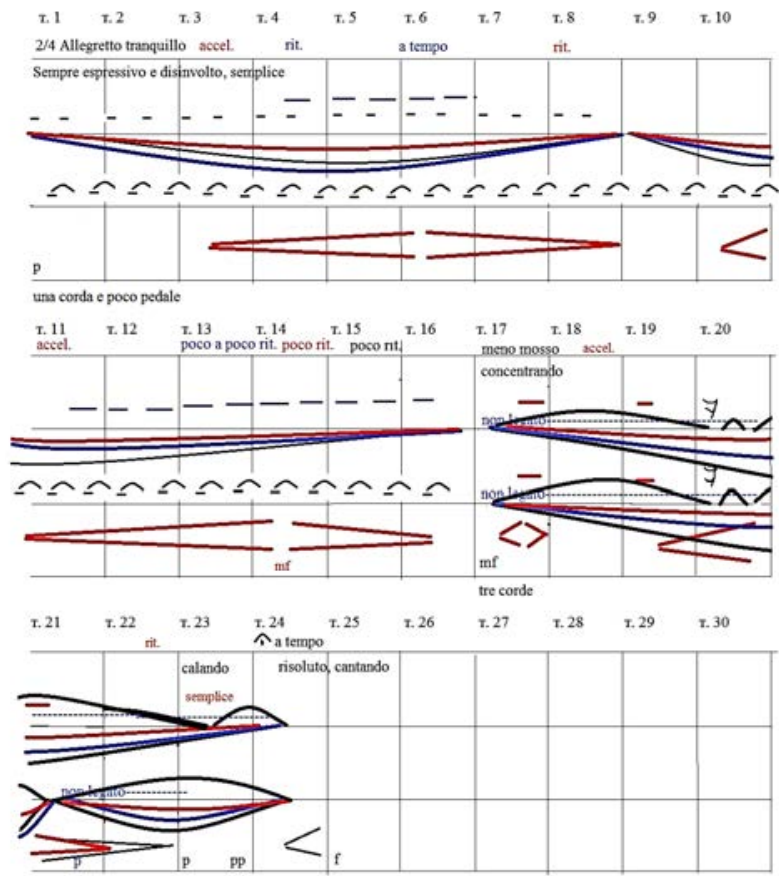

Сравнительная «Исполнительская партитура ремарок»:

1. Ремарки Метнера (выделены жииным черным цветом);

2. Интерпретация Э. Гилельса (выделена красным цветом);

3. Интерпретация С. Рихтера (выделена синим цветом).

Указанная партитура позволяет представить объективную картину особенностей интерпретаций сонатного творчества Н. Метнера в контексте разнообразия национальных исполнительских школ и индивидуальной природы исполнительской манеры великих пианистов прошедшего и нынешнего веков. Одновременно подчеркнем, что она призвана обращать 
внимание на технологические особенности исполнительского процесса с их музыкально-выразительной стороны, что позволяет судить обо всем объеме исполнительской семантики, и создает существенные предпосылки для выявления образно-смысловых предпочтений интерпретаторов.

Таким образом, магистральное направление современного исполнительского понимания - интерпретации фортепианных сонат Н. Метнера можно определить как хронотопическую концептуализацию, позволяющую находить место фортепианной поэтики Н. Метнера в историческом времени музыки, которое может сохраняться, расширяться и воспроизводиться именно как свободное стилевое - свободное от частной темпоральной приуроченности и топонимической зависимости, одновременно - как создающее новое семантическое измерение музыкального творчества.

\section{СПИСОК ЛИТЕРАТУРЫ}

1. Васильев П. Фортепианные сонаты Метнера. Москва : Музгиз, 1962. $44 \mathrm{c}$.

2. Гольденвейзер А. Воспоминания о Н.К. Метнере. О музыкальном искусстве. Москва : Музыка, 1975. С. 58.

3. Нейгауз Г. Размышления, воспоминания, дневники. Избранные статьи. Письма к родителям. Москва : Сов. комП., 1983. 197 с.

4. Мясковский Н. Статьи. Письма. Воспоминания : в 2-х т. / ред. С. Шлифштейн. Москва : Сов. композитор, 1958 - 1960. Т. 1. 358 c. ; T. 2.110 c.

5. Трояновская А. Жизнь Н.К. Метнера в Буграх. Воспоминания. Статьи. Материалы / Н. Метнер. Москва : Сов. композитор, 1981. $136 \mathrm{c}$.

6. Зетель И. Н.К. Метнер - пианист. Творчество, исполнительство, педагогика. Москва : Музыка, 1981. 127 с.

7. Сокол А. Исполнительские ремарки, образ мира и музыкальный стиль. Одесса : Моряк, 2007. 36 с.

\section{REFERENCES}

1. Vasiliev P. Piano sonatas of Medtner. M .: Muzgiz, 1962. 7-43 p.

2. Goldenweiser A. Memories of N.K. Metner. Goldenweiser A. About musical art. M .: Music, 1975. 58 p.

3. Neuhaus G. Reflections, memories, diaries. Selected articles. Letters to parents. Moscow: Sov. comp., 1983. 197 p.

4. Myaskovsky N. Articles. Letters. Memories: in 2 tons / ed. S. Shlifstein. Moscow: Sov. composer, 1958 - 1960. T. 1. 358 p .; T. 2. 110 p.

5. Troyanovskaya A. Life of N.K. Medtner in the Bugry. N.K. Medtner. Memories. Articles. Materials. Moscow: Sov. composer, 1981. $136 \mathrm{p}$.

6. Zetel I.N.K. Medtner is a pianist. Creativity, performance, pedagogy. M. Music, 1981. 79, $127 \mathrm{p}$.

7. Sokol A. Performing remarks, the image of the world and the musical style. Odessa: The Seaman, 2007. 36 p. 